\title{
Objetos de Aprendizagem na Educação Infantil
}

Carmen Vieira Mathias - UNIFRA - carmen@unifra.br

Janilse Fernandes Nunes Vasconcelos- UNIFRA - janilse@ unifra.br

Solange Binotto Fagan - sfagan@ unifra.br

\section{RESUMO}

As dificuldades enfrentadas pelo professor na prática docente aumentam à medida que as crianças pequenas encontram, fora da escola de Educação Infantil meios mais atrativos de entretenimento e aprendizagem. As tecnologias digitais nas escolas surgem com a finalidade de proporcionar as crianças pequenas formas diferenciadas e mais prazerosas de interação, para desenvolver as atividades do cotidiano da sala de aula. Este trabalho apresenta as experiências obtidas na produção de objetos de aprendizagem, que tem como pressuposto conceitual a reutilização nos diferentes níveis de ensino, que busca proporcionar ao aluno que o utiliza, uma aprendizagem de maneira interativa. É importante salientar que a exploração das atividades, possibilita as crianças o entendimento dos principais conceitos envolvidos, pois existe uma interação dos mesmos no processo, o que possibilita a reflexão-ação-reflexão.

Palavras - chave: ludicidade; Educação Infantil; educação digital; objetos de aprendizagem

\section{ABSTRACT}

The difficulties faced by teachers in teaching practice increase as the children are out of school for Child Education means more attractive entertainment and learning. Digital technologies in schools are aiming to provide young children more pleasant and different forms of interaction, to develop the daily activities of the classroom. This paper presents the experiences obtained in the production of objects of learning, which is the prerequisite conceptual reuse at different levels of education, which seeks to provide that the student uses an interactive way of learning. It is important to note that the farm activities, enable children to understand the main concepts involved, there is an interaction in the same process, which allows reflection-action-reflection

Keywords: ludicidade; Child Rearing; digital education; Object of learning

\section{INTRODUÇÃO}

As demandas educacionais são significativas em relação à tecnologia digital e o cotidiano escolar da Educação Infantil, pois o acesso aos computadores e a Internet, redimensionaram o uso das tecnologias nos processos de ensino e aprendizagem. Esse artigo ressalta especificamente na potencialidade do computador que já está inserido no contexto da escola, e que é utilizado com um meio para desenvolver atividades que possibilitem um alto grau de interatividade por parte das crianças.

Pesquisas recentes publicadas pelo Instituto Brasileiro de Opinião Pública e Estatística - IBOPE revelam que 33,1 milhões de brasileiros entre crianças, jovens e adultos acessam a Rede Internacional de Comunicação, popularmente conhecida como Internet. Sabe-se que uma grande porcentagem desta população está entre crianças e adolescentes, que fazem o uso desta tecnologia sem qualquer orientação prévia, sendo a Internet uma 
ampla rede de divulgação e de todos os tipos de informações, muitas vezes inadequadas para a infância.

De acordo com Lévy (2002, p. 14), “a Internet é um espaço de comunicação propriamente surrealista, do qual "nada é excluído", nem o bem, nem o mal, nem suas múltiplas definições, nem a discussões que tende a separá-las sem jamais conseguir." A Internet possibilita a interação e envolve as diferentes culturas, com uma relação sem hierarquia, pois possibilita que as pessoas explorem-a conforme a sua necessidade.

Mas como utilizar a internet, na prática docente, com objetivos definidos, respaldados na aprendizagem do aluno?

Uma das ações que temos é uma ação da Secretaria de Educação à Distância do Ministério da Educação que tem buscado oportunizar aos estudantes universitários do Brasil a produção de Objetos de Aprendizagem (OAs), visando à melhoria e a inovação dos processos de ensino e aprendizagem em diferentes áreas de conhecimento. Segundo Nascimento (2005), entende-se por Objeto de Aprendizagem, qualquer recurso que possa ser reutilizado para dar suporte ao aprendizado.

Estudos recentes têm mostrado que os Objetos de Aprendizagem podem ser uma alternativa pedagógica eficaz no ensino dos conteúdos inseridos na proposta de trabalho. $\mathrm{O}$ planejamento das atividades deve possibilitar que as crianças reflitam e busquem as respostas para suas dúvidas realizando as conexões com o seu cotidiano. Os Objetos de Aprendizagem são referenciados neste artigo, como a tecnologia que vem contribuir para a aprendizagem na Educação Infantil, visto que a criança, pro meio da mediação do professor faz as relações com os conhecimentos prévios que ela possui em relação ao assunto e consegue fazer as conexões e dar um novo significado ao conhecimento.

\section{OBJETOS DE APRENDIZAGEM}

O Objeto de Aprendizagem (OA) se caracteriza por um recurso digital que deve dar conta de um conteúdo, com uma finalidade educacional específica, que é de facilitar o entendimento dos principais conceitos envolvidos, neste caso, o Ciclo da Água e as principais operações matemáticas (adição, subtração, divisão e multiplicação), estes seriam dois objetos para os alunos do Ensino Fundamental, mas aqui neste artigo temos a intenção de mostrar o potencial do OAs na sua condição de reutilização para a Educação Infantil. Entendemos por um OA reutilizável, aquele que pode ser utilizado em diferentes contextos, que aqui no caso seria o Ensino Fundamental e a Educação Infantil. Ambos os OAs propiciam que a criança exercite as atividades propostas, e no final faça uma avaliação, na realização de um feedback do conteúdo para que ela mesma, possa fazer uma análise dos resultados, tendo como possibilidade de voltar e refazer as atividades.

Além disso, nos dois objetos que iremos descrever posteriormente, existem atividades assíncronas que os compõem e estão relacionadas com o conteúdo, das mais diversas formas, bem como: animações, atividades e simulações, o que possibilitam a exploração diversificada, mas sempre focalizada ao objetivo pedagógico que o OA se propõe, podendo ser utilizado em diferentes contextos, caracterizando a sua reutilização.

\section{CENÁRIO DA PRODUÇÃO DOS OBJETOS DE APRENDIZAGEM}

Nossa Instituição de Ensino Superior conta, com uma equipe de capacitação, avaliação e produção de OAs, formada por dois grupos. O primeiro é composto por alunos de graduação, pós-graduação e professores de diferentes áreas do conhecimento (Pedagogia, Física, Geografia, Matemática entre outros), e o segundo, que denominamos 
grupo de suporte técnico, é composto por alunos dos cursos de Ciência da Computação, Design e Comunicação.

Nossa equipe realizou um programa de capacitação, com o objetivo de transmitir aos grupos, as informações necessárias para entender a metodologia difundida para a construção de materiais didáticos digitais. Essa capacitação nos oportunizou entender o processo de desenvolvimento dos Objetos de Aprendizagem, segundo a metodologia proposta, pela equipe do RIVED, que é um programa vinculada a Secretaria de Educação à Distância - Seed, do Ministério da Educação - MEC, que é tem suas especificidades para a produção em função da organização dos metadados ${ }^{1}$ no Repositório. Maiores informações sobre a metodologia utilizada pelo grupo podem ser encontradas em ALCIBÍADES, ET. AL. (2006). Salientamos também que os OAs desenvolvidos pela equipe da UNIFRA já se

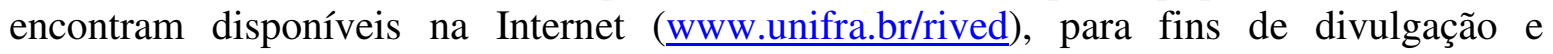
exploração dos mesmos.

\section{DESENVOLVIMENTO DO OBJETO DE APRENDIZAGEM: SUPERMERCADO VIRTUAL}

O OA propõe uma atividade que versa sobre o tema "Compras Virtuais em um Supermercado", oportuniza a interação de forma diversificada, a fim de auxiliar nos processos de ensino e aprendizagem. Essa atividade propicia a utilização do dinheiro de forma reflexiva: a partir da pesquisa, da comparação de preços e permite que o aluno ao interagir tenha autonomia para gastar, mas faz o aluno repensar na economia no momento da compra.O principal objetivo para os alunos do $2^{\circ}, 3^{\circ}$ e $4^{\circ}$ ano do Ensino Fundamental, é o de facilitar o entendimento das principais operações matemáticas (adição, subtração, divisão e multiplicação) em relação à utilização do dinheiro.

A tela inicial, é o que chamamos tela de apresentação, onde o carrinho, que é o nosso agente pedagógico, conforme mostra a Figura 1, convida o aluno a fazer as compras da semana. O aluno poderá escolher entre menino e menina, e assim que preencher os dados, ele "clica" em avançar e vai para a segunda tela. Como podemos observar na Figura 2, essa possui um espaço para um pequeno cadastro, que será impresso no final, junto com a "nota fiscal".

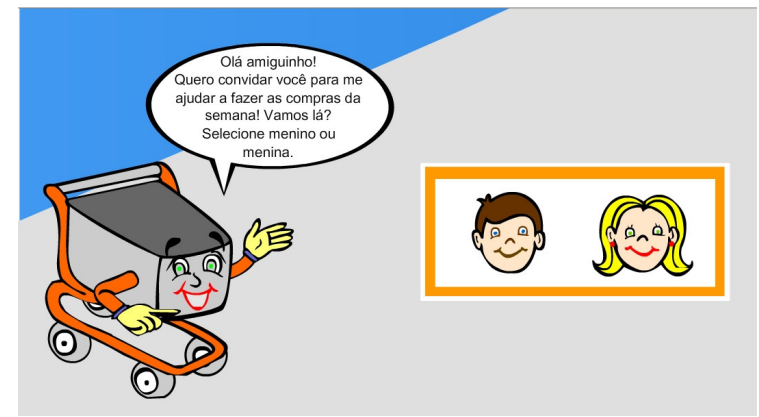

Figura 1 - Tela de apresentação.

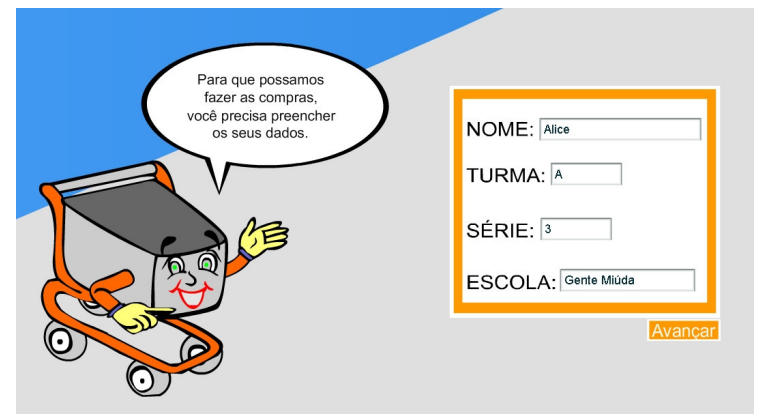

Figura 2 - Apresenta um espaço, para que o aluno faça o seu cadastro.

${ }^{1}$ Para Togni (2007), os metadados são os dados que descrevem os conteúdos dos arquivos digitais. Eles são como etiquetas que descrevem o conteúdo dos objetos, o tamanho, a aplicação e demais informações que os desenvolvedores consideram importantes. 
Assim que o aluno preencher os dados e clicar em avançar é remetido para a terceira tela (Figura 3), que apresenta a lista de compras, que deverá ser adquirida e um caixa eletrônico, onde o aluno simulará a retirada de certa quantia, até o limite máximo de $\mathrm{R} \$$ 40,00 .

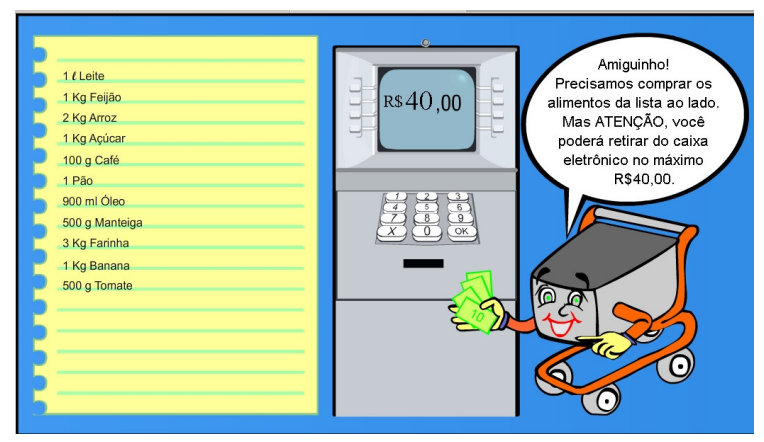

Figura 3 - Apresenta a lista de alimentos que o aluno precisa comprar, e o caixa eletrônico

Nessa tela, o aluno clicará nos botões do caixa eletrônico, e poderá prosseguir a atividade clicando em avançar, para ir na quarta tela, conforme mostra a Figura 4.

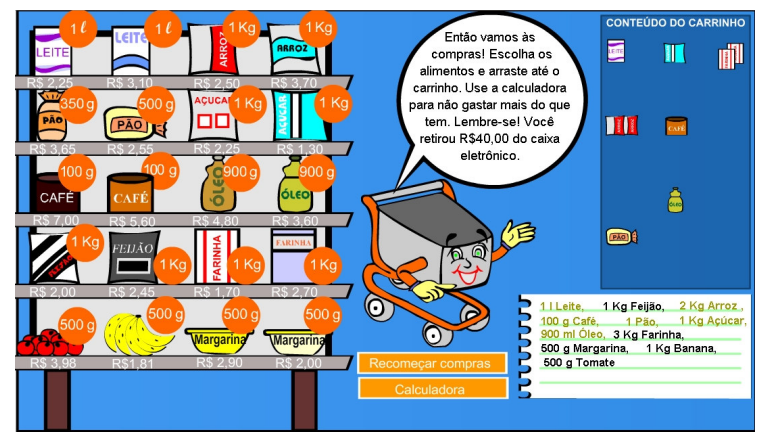

Figura 4 - Nesta tela, o aluno fará as compras.

Nessa etapa da atividade, o aluno arrastará o item escolhido para dentro do carrinho. A cada produto que o aluno arrastar para o carro, aparecerá um traço, para indicar que a compra já foi feita. Quando o aluno acabar de fazer suas compras, ele deverá clicar em avançar para ir até a próxima tela, conforme podemos ver na Figura 5. Porém, se faltar algum item da lista o carrinho "avisará", antes que o aluno avance.

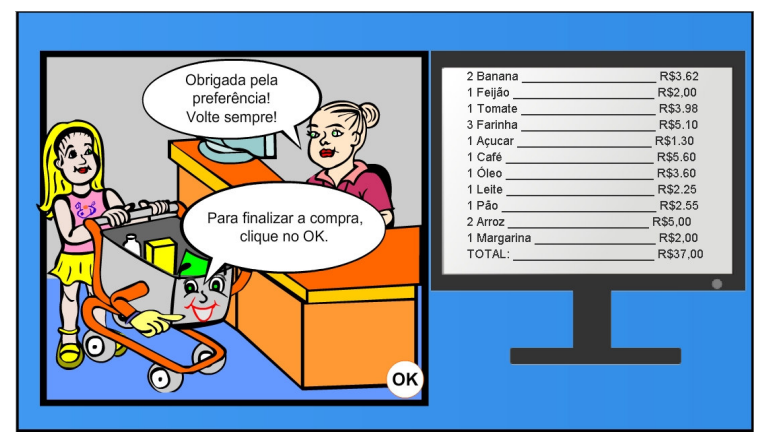

Figura 5 - Nesta tela, o aluno passará no caixa, para registrar os produtos que comprou. 
Nesta etapa, o aluno já realizou todas as compras, então aparece a "nota fiscal", onde constam todos os itens comprados e onde serão utilizados os dados que foram preenchidos pelo aluno no início do Objeto, potencializando a importância de levar a sua nota fiscal para casa. Na tela final do objeto (figura 6), aparece o porquinho, que parabeniza o aluno pela compra e pela economia que fez.

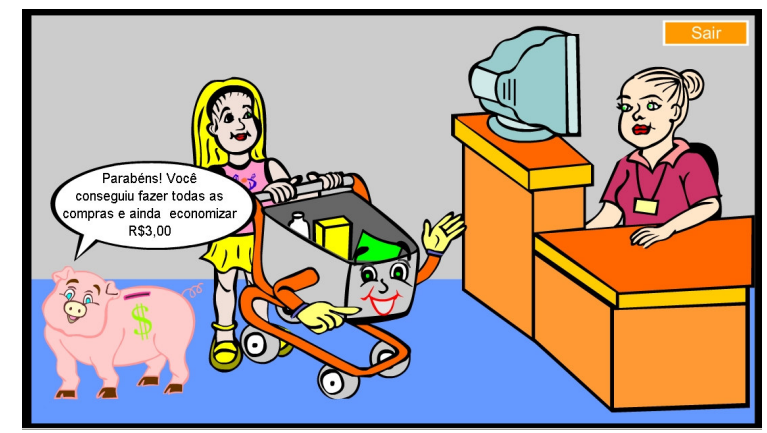

Figura 6 - Tela final,mostra o quanto o aluno conseguiu poupar.

\section{DESENVOLVIMENTO DO OBJETO DE APRENDIZAGEM: CICLO DA ÁGUA}

$\mathrm{Na}$ construção do Objeto, trabalhamos com a temática, Ciclo da Água, tema escolhido por meio de pesquisa realizada com alunos de $3^{a}$ a $4^{a}$ séries dos Anos Iniciais do Ensino Fundamental, que relatam ter dificuldades na compreensão dos conceitos e suas relações. Com este propósito, construímos um Objeto de Aprendizagem, que tem por objetivo apresentar o tema de forma lúdica, dinâmica, criativa e interativa, o Ciclo da Água no planeta auxiliando na compreensão das etapas do processo. Ao compreender o Ciclo da Água, o aluno passará a identificar como acontece o ciclo. Esta compreensão é muito importante, visto que o ciclo contribui para a formação de rios e lagos, fontes de água potável e permite a manutenção da vida na Terra, sendo também responsável pela renovação da água no planeta.

O Objeto Ciclo da Água apresenta como personagem à "Gotinha" (Figura 7), personagem este, que é caracterizado com Agente Pedagógico, sendo incumbido a ele a interação entre Objeto e o aluno. Os alunos são convidados pela "gotinha" a descobrirem o caminho do Ciclo da Água e as etapas na natureza.

No próximo passo a gotinha convida-o para preencher o cadastro (Figura 8), identificando nome, série, turma e escola, sendo que este será impresso no final da atividade, com o propósito, de ser realizada pelo professor da turma, uma avaliação da aprendizagem dos alunos.

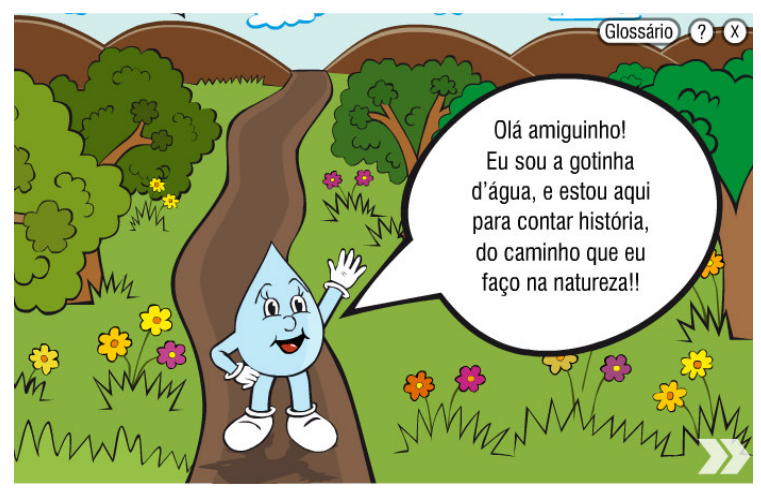

Figura 7 - Apresentação do Agente Pedagógico

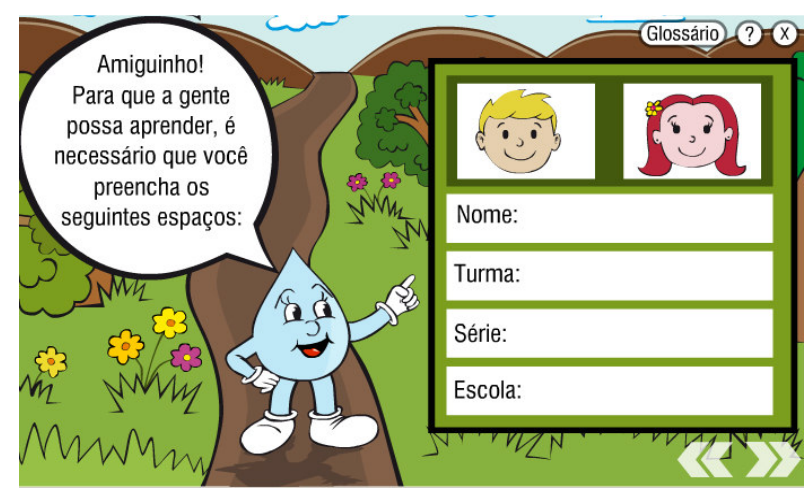

Figura 8 - Cadastro do aluno 
Em um segundo momento, a gotinha convida o aluno a escolher um dos processos do Ciclo da Água para iniciar. Quando o aluno escolher um processo deverá clicar sobre a palavra que deseja, CONDESAÇÃO, PRECIPITAÇÃO, TRANSPIRAÇÃO OU EVAPORAÇÃO, conforme mostra a figura 9.

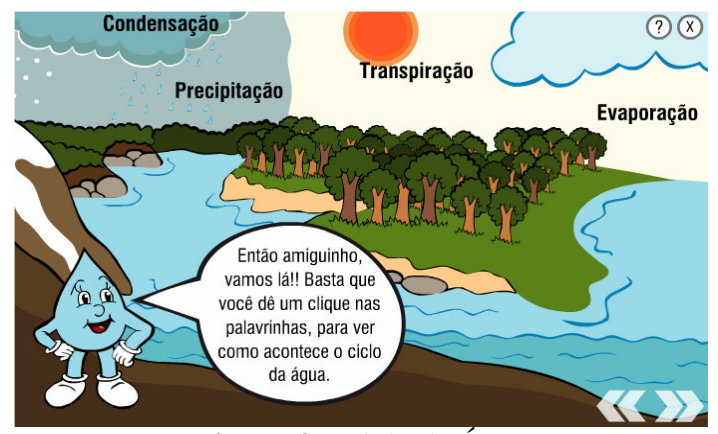

Figura 9 - Ciclo da Água

Ao clicar, por exemplo, em Precipitação, abrirá uma tela sobreposta à imagem, que terá uma animação referente ao processo escolhido, veja a figura 10.

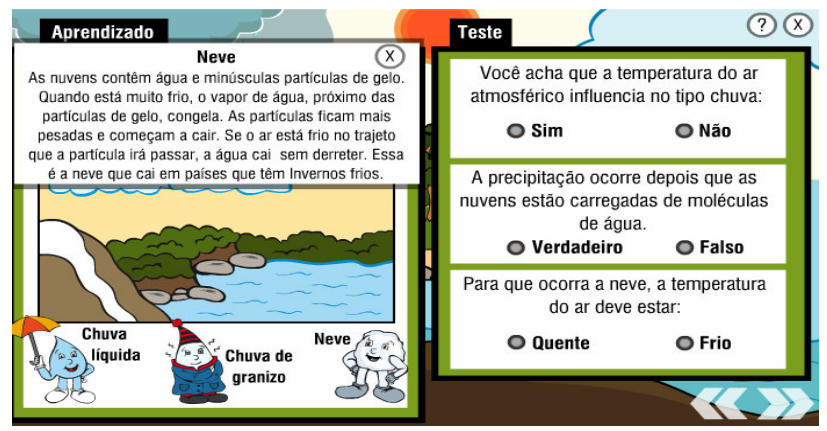

Figura 10 - Processo de Precipitação.

As animações apresentadas em cada processo, disponibilizarão ao aluno questionamentos, onde ele deverá responder para prosseguir. O aluno perpassará por todos os processos, respondendo a todos os questionários. A cada finalização de um processo, ele voltará para a tela 3, (figura 9), e o ciclo se movimentará, correspondendo ao processo escolhido pelo aluno. Esta tela proporciona simulações muito parecidas com a realidade, permitindo um conhecimento amplo que muitas vezes na sala de aula, não é possível devido a pouca acessibilidade a recursos extras. Depois ter passado pelas quatro etapas do processo do ciclo da água, haverá uma tela final, na qual o aluno será convidado pela gotinha a arrastar as palavras para dentro do ciclo, colocando-as nos respectivos lugares (figura 11).

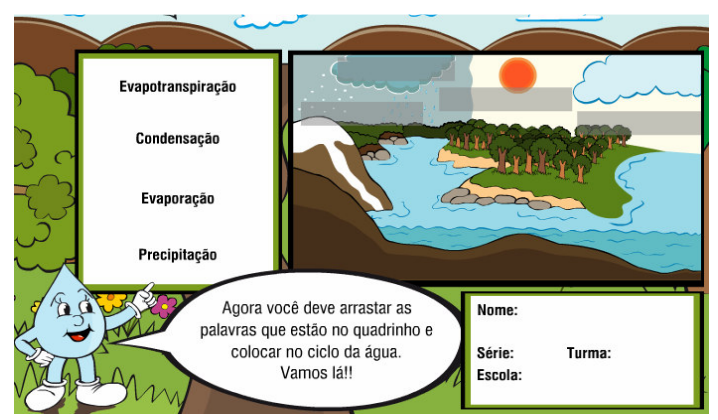

Figura 11 - Feedback 
Após a inserção das palavras nos lugares, haverá um ícone para que o aluno possa imprimir a atividade final (figura 11) e entregar para a professora, que fará a avaliação do desempenho do aluno, proposto pelo Objeto de Aprendizagem Ciclo da Água. É importante ressaltar que a temática "Água” pode ser explorada em diversos âmbitos e áreas do conhecimento, considerando a sua abrangência e importância para a humanidade, por isso cabe ao professor decidir a melhor maneira para explorar este tema, juntamente com o Objeto.

\section{REUTILIZAÇÃO DOS OBJETOS DE APRENDIZAGEM NA EDUCAÇÃO INFANTIL}

Objetos de Aprendizagem significa material didático digital, com a característica da padronização no armazenamento e reutilização, ou seja, seu uso pode ser compartilhado o que exige que ele tenha uma estrutura modular associada com o desenvolvimento direcionado para a web. Pode ser formado por uma lição, pelo conteúdo de uma aula, de um curso, um programa de treinamento, uma unidade curricular ou uma atividade didática qualquer (GAZZONI, et. Al, 2006).

A reutilização é o conceito fundador o qual implica que a concepção do OA siga um conjunto de normas rigorosas de produção através das quais será possível articular aspectos como a combinação e a granularidade da unidade ou conteúdo numa nova sequência de aprendizagem (DIAS, 2005 p.3).

Analogamente, os OAs surgiram como forma de organizar e estruturar materiais educacionais digitais tendo em vista sua reusabilidade. A reusabilidade pressupõe também a existência de um sistema de catalogação dos OAs com vistas a assegurar acessibilidade, pela possibilidade de acessar recursos educacionais em um local remoto e usá-los em muitos outros locais. Portanto, o OA é mais eficientemente aproveitado quando organizado, catalogado e armazenado em um repositório integrável a um sistema de gerenciamento de aprendizagem (Learning Management System - LMS) (TAROUCO; DUTRA, 2007, p. 82).

Principalmente na Educação Infantil, o Objeto de Aprendizagem, deve ter um caráter lúdico, pode ser visto e revisto como um jogo que possibilita uma exploração e consequentemente uma aprendizagem. Pois no ato de brincar, as crianças possuem uma rica interação com os colegas, desta forma progressivamente vão ampliando o seu vocabulário e se socializando, por isso quando senta em dupla para explorar o Objeto fazem suas conexões com a sua realidade.

Os jogos e as brincadeiras são atividades naturais, espontâneas e necessárias. Ao brincar, a criança entra em um clima lúdico e usa o simbolismo. Quando brinca, a criança desenvolve a sociabilidade e aprende a conviver, aprendendo a respeitar o direito dos outros e as normas estabelecidas pelo grupo. E é assim que os Objetos devem ser explorados, como se fossem jogos, em que a professora faz os encaminhamentos respaldados pelo Guia do Professor, de acordo com objetivos vinculados a atividade proposta.

O OA do Supermercado pode ser explorado a alimentação, que tipos de produtos tem disponível na prateleira e encaminhar uma classificação, que pode ser realizada por meio de um desenho ou com brinquedos que representem os alimentos. Já no OA do Ciclo da Água, pode ser encaminhado atividades que envolvam a idéia de Tempo, temperatura, vestimentas adequadas. Ao brincar, a criança se desenvolve, exercitando suas potencialidades e aprende com prazer. 


\section{CONCLUSÕES}

Estamos vivendo uma época de muitas reflexões sobre o processo de aprender, tendo como meio a tecnologia digital, e com esse pressuposto o computador deve ser inserido na educação. No Objeto de Aprendizagem de Compras Virtuais, envolve valores reais em situações de compra e propicia a ampliação da habilidade de calcular de maneira aproximada, rápida, usando procedimentos simples. O processo de construção do OA possibilita encontros e diálogos possíveis entre o que chamamos da área técnica e pedagógica, possibilitando a interdisciplinaridade. Verificamos também que a construção destes Objetos, possibilitam aos alunos do ensino superior, a condição de compreender de maneira efetiva como se dá os processos de ensinar e de aprender, vivenciando a construção do conhecimento na totalidade da produção do OA, tornando esse aluno um protagonista ativo e autônomo, que vive na prática a necessidade do trabalho em equipe, interdisciplinar com enfoque no diálogo e nas conexões relacionadas ao conhecimento.

\section{REFERÊNCIAS BIBLIOGRÁFICAS}

GAZZONI, ET. AL. (2006). Proporcionalidade e semelhança: aprendizagem via objetos de aprendizagem.

Disponível em: http://www.cinted.ufrgs.br/renote/dez2006/artigosrenote/25179.pdf

DIAS, Paulo. Desenvolvimento de objectos de aprendizagem para plataformas colaborativas. In Nelson de Luca Pretto, (Org.), Tecnologias e Novas Educações. Salvador: Faculdade de Educação da Universidade Federal da Bahia, 2005.

FARIA C.O.; REIS C.F. (2003). Uma Apresentação do RIVED - Rede Internacional Virtual de Educação. Disponível em: http://www.rived.mec.gov.br/artigos/ciaem.pdf.

LÉVY, P. Uma perspectiva vitalista sobre a cibercultura. In: LEMOS, André. Cibercultura: tecnologia e vida social na cultura contemporânea. Porto Alegre: Sulina, 2002.

MONTEIRO, B.S. (2006) Metodologia de desenvolvimento de objetos de aprendizagem com foco na aprendizagem significativa. Disponível em: < www.rived.mec.gov.br/artigos/>.

NASCIMENTO, A. C. (2004) Taking The Next Step with The Project RIVED, World Conference on Educational Multimedia, Hypermedia \& Telecommunications Lugano, Switzerland. Disponível em: http://www.rived.mec.gov.br/artigos /nextstep.pdf.

NASCIMENTO, A. C. (2005) Construindo Comunidades de Elaboradores de Objetos de Aprendizagem através de Conteúdo, MEC, Disponível em: http://www.rived.mec.gov.br/artigos/.

SILVEIRA ,A. M. et al. (2005) Desenvolvimento de um Objeto de Aprendizagem sobre a Poluição Global. Revista Novas Tecnologias na Educação - CINTED -- Vol. 4 No 2.

TAROUCO, Liane; DUTRA, Renato Luis de Souza. Padrões e interoperabilidade. In: Carmem Lucia Prata, Anna Christina Aun de Azevedo Nascimento. (Org.). Objetos de Aprendizagem - Uma proposta de recurso pedagógico. Brasília - DF: MEC/SEED, 2007, v. , p. 81-92. 